\title{
Theoretical Analysis of the Vascular System and its Relation to Adrian Bejan's constructal Theory
}

\section{E Roux ${ }^{1,2}$, M Marhl ${ }^{3,4,5}$}

${ }^{1}$ Université Paris 1 Panthéon-Sorbonne \& CNRS, UMR 8560 IHPST - Institut d'Histoire et de Philosophie des Sciences et des Techniques, Paris, France

${ }^{2}$ Univ. Bordeaux, Inserm, UMR1034, Biology of Cardiovascular Diseases, F-33600 Pessac, France

3 Department of Physics, Faculty of Natural Sciences and Mathematics, University of Maribor, Maribor, Slovenia

${ }^{4}$ Faculty of Education, University of Maribor, Maribor, Slovenia

${ }^{5}$ Institute of Physiology, Faculty of Medicine, University of Maribor, Maribor, Slovenia

submitted: Apr 1, 2017, accepted: Jun 15, 2017, EPub Ahead of Print: Jun 26, 2017

Conflict of interest: none

DOI: 10.24019/jtavr.20 - Corresponding author: Assoc. Prof. Etienne Roux, etienne.roux@u-bordeaux2.fr,

(C) 2017 Fondazione Vasculab impresa sociale ONLUS. All rights reserved.

\begin{abstract}
Basically, the main function of the cardiovascular system is to provide oxygen and other nutriments to the tissues, achieved by the pumping action of the heart and the subsequent blood flow through the tree-like vasculature. Classically, in the physical and mathematical analysis of the relationship between form and function of vascular systems, form is given first. The constructal theory, first proposed by Adrian Bejan in 1996, is a thermodynamic principle according to which flow systems, such as watersheds and vascular networks, evolve so that they gain more global performance over time. There are two major points about the constructal theory. The first one is that it provides a unifying concept of form and function, in which the configuration is not postulated, but is to be discovered. The second one is that it is presented as a unifying physical concept of evolution of organic and inorganic flow systems. By comparing non-living (watersheds) and living (vasculature) systems, we show that the processes of morphological "change upon time" in watersheds and those of developmental morphogenesis and evolutionary modifications through generations in a population are not equivalent. Mechanistic explanations in biology include physico-mathematical models but, from the biological point of view, the epistemic value of the constructal law is not its unifying power by subsumption of biological processes under a general nomological principle,
\end{abstract}

but, to the contrary, to provide an idealized physicomathematical model of living systems that is embedded in general mechanistic explanatory frameworks of biological processes such as development and evolution.

Keywords network, self-organization, causality, evolution, morphogenesis

\section{Introduction}

\section{Form and function of vascular networks}

The cardiovascular system is a canonical example of ascription of a biological function. Since William Harvey's book publication in $1628^{1}$, in which he evidenced the existence of the circulation of the blood in the vessels, the structure and the functional properties of the vasculature has been extensively studied. Basically, the function of the cardiovascular system is to ensure fast transport of matter and energy, and, in particular, to provide oxygen and other nutriments to the tissues, achieved by the pumping action of the heart and the subsequent blood flow through the vasculature. Oxygen delivery to the tissues occurs via two combined mechanisms, oxygen transport via blood convection throughout the arterial, capillary and venous 
networks $^{[i]}$, and oxygen diffusion through the capillary walls to the mitochondria within the cells, where oxygen is used by the aerobic process of energy production $^{2,3}$. According to its function, as identified by biologists, the functional efficency of the vasculature, i.e., the properties of the system that determine the flow rate of oxygen delivered to the tissues, has been analyzed in physical terms: fluid mechanics and the physical properties of the blood, solid mechanics and the properties of vessel walls, laws of diffusion, allometry, etc. Physiological textbooks have usually a summary of the basic physics of circulation ${ }^{3}$, and specialized textbooks are dedicated to the biomechanics of the circulation ${ }^{4,5}$.

Functional analysis of vascular networks based on their physical properties should also consider their structures. Taken altogether, the total length of the vessel segments in a human body is around $100000 \mathrm{~km}$. These segments and their connections form a highly hierarchical structure, similar to that of a tree and its branches. The morphological analogy between the branched organization of blood vessels and trees had been noticed by early physiologists such as Jean Fernel, even prior to the discovery of blood circulation by William Harvey 6,7 . Despite the differences between a tree and a vascular network, and the interindividual variations in their detailed geometry, all these structures share a common kind of pattern, based on the fact that they are multiscale branched structures. These patterns can be found not only in living systems such as vasculatures, bronchial arborescences, trees and branches, but also in non-living systems such as river basins.

Beyond angiology, the anatomical description of the vessels, several mathematical concepts and tools have been used to grasp the apparent complexity and variability of the vascular networks and to provide a quantitative characterization of their patterns. The Strahler number, which is a numerical measure of the branching pattern of a mathematical tree, has been used to provide a rankordered topology of the vasculature. Interestingly, this mathematical tool was first developed in hydrology for the analysis of river networks 8 , and later used for the analysis of biological hierarchical patterns such as respiratory and vascular systems $^{9-13}$. The emergence of fractal geometry has also provided a mathematical concept initially applied to non-living systems but quickly extended toward life sciences $^{14,15}$. Actually, biological structures are not pure fractals, but, in a given range, may exhibit fractal properties, i.e., exhibit the same design at different scales. Whether a given network has fractal characteristics should not be taken a priori, but as a hypothesis that requires empirical validation. An abundant literature has been devoted to the fractal properties of biological features (see, for a review,
$\operatorname{Losa}^{15}$ ), among them the pattern of the vascular network ${ }^{10,}$ $13,16,17$, which have been described as a combination of scale-invariant and scale-specific patterns17. What it is important to notice is that these kinds of structural analysis of vascular networks are grounded on physicomathematical concepts and tools.

The combination of these mathematical descriptions of the pattern of the circulatory system with the biomechanics of the circulation have been done to provide physical interpretations of the functional capacity of the vascular system (see for example ${ }^{13,18,19}$. Two interesting remarks can be done about this way to analyze the vascular system. First, the mathematical and physical methodology and concepts used for such an analysis are not specific to biological systems. In particular, it seems that it exists a deep analogy, both in pattern and functionality, between non-living systems, like hydrologic basins, and living ones, like vascular networks, throughout which flows a fluid. For example, the Strahler order had been initially developed for the analysis of watershed morphology, and applied later to airway and vascular networks. Comparison of the functional properties of irrigation fields and blood circulation is done by physicists themselves:

"There are infinite variations in the detailed geometry of microvascular beds, just as there are infinite varieties of irrigation fields in agriculture." [...] "To help visualize the difference between [glomerulus, sinusoid and sinus network] models, analogous agricultural irrigations are sketched on the side. ${ }^{\prime 5}$

Second, in the combination of form and function, the pattern of the structure is given first, and not understood as the consequence of the flow of the fluid throughout the system, as illustrated by the methodology explained by Fung:

"As usual, we shall start with anatomy, then proceed to the mechanical properties of the tissues, and finally, to system dynamics. The importance of the subject is unquestionable because the whole purpose of the heart and arteries is to carry blood to the capillaries to nourish the cells of the body." 5

\section{The constructal theory}

The constructal theory, first proposed by Adrian Bejan in 1996, is a thermodynamic principle according to which flow system, such as watersheds and vascular networks, evolve so that they gain more global performance over time ${ }^{20-22}$. Based on the principle of global optimization, i.e., minimization of the entropy generation, of local constraints, the principle of the constructal theory is, according to its author, as follows ${ }^{21}$ : 
"Constructal theory is the view that the generation of flow configuration is a universal phenomenon of all physics. [...] This law is about the necessity of design to occur."

According to Bejan, the constructal law is the last of the three laws of thermodynamics, to each of which he attributes a self-standing tendency in nature: energy conservation for the first one, irreversibility for the second one, and evolution for the third one the so-called constructal law, which he himself summarizes ${ }^{23}$ :

"For a finite-size flow system to persist in time (to live) it must evolve freely such that it provides greater access to its currents."

There are two major points about the constructal theory. The first one is that it provides a unifying concept of form and function. Contrary to Fung's methodology, form is not given first ${ }^{23}$ :

"We did not postulate the configuration: in fact, in the physics of evolution the configuration is unknown [...] In the physics of evolution, the boundaries (the drawings) are to be discovered".

The constructal law hence predicts the evolution upon time of the pattern of a flow system to the least imperfection, i.e., the design of the system that provides minimal global resistance to the flow. The emergence of some morphological characteristics, such as the fractal structure of watershed, vessel networks, airway tree is, according to the constructal theory, the thermodynamical consequence of flow.

"Organization of the real (system) scale appears to be a collage of the same design from smaller scales. This is an appearance, but its basis is physics, and it has nothing to do with fractal geometry. It has everything to do with flow and the free morphing of architecture toward greater access". 23

The constructal theory has been applied to a variety of systems, including biological flow systems like the Mammalian bronchoalveolar lung ${ }^{24}$ and several Mammalian circulatory networks ${ }^{[i i] 25-27}$. Recently, based on the constructual law applied to vascular systems, an evolution parameter $\mathrm{EV}_{\mathrm{V}}$, defined as the ratio of the global flow conductance of the evolving configuration on the global conductance of the configuration with least imperfection, has been proposed to quantity the evolutionary value of the network configuration with regard to the configuration of least imperfection, as predicted by the constructal law ${ }^{27}$.

The second important point of the constructal theory is that it is presented as a unifying physical concept of organic and inorganic flow systems. As an example, the first line of an article written by $\operatorname{Bejan}^{21}$ is:

"Why are lungs and river basins 'vascular'?"

According to the constructal theory, the reason is that the type of stress that the water flow exerts on the river bed is similar to the type of stress that the blood flow or the air flow exerts on the vascular network and the bronchial network, respectively $24,27,28$. The same laws determine the systems of inanimate and animate flows. Watersheds, lungs and blood vessels exhibit similar patterns because there are submitted to the same physical principle of flow optimization.

"We show that the emergence of scaling laws in inanimate (geophysical) flow systems is the same phenomenon as the emergence of allometric laws in animate (biological) flow systems." 21

According to Adrian Bejan, the constructal law not only provides explanations about the relationship between form and functionality in biological and nonbiological systems, but it unifies life and non-biological processes under the same nomological principle. Under the constructal law, life and evolution are physics ${ }^{23}$.

\section{The explanatory value of the constructal theory}

We do not question the epistemological status of the constructal law in physics, compared to the first and second principles of thermodynamics, nor the validity of the generalization of the constructal law to universal properties, as Bejan himself claims:

"In conclusion, the constructal law is the law of physics of life and evolution everywhere, animate and inanimate, and at all scales, from vascular tissues to celestial bodies." 23

We will limit our discussion to the epistemic significance of the constructal law with regard to vascular tissues. For this purpose, we will compare the application of the constructal theory to watersheds versus vascular networks. The reason of such a comparison is that, as noticed previously, the analogy between circulatory systems and watersheds has already been done, and that Adrian Bejan and other partisans of the constructal theory have also applied it to both types of systems, as an example of its unifying power.

If we take the examples of the hydrological and vascular networks, the constructal theory says that the similarities in the structure of these networks are explained by the fact that their construction responds to the same type of constraints that lead to the overall optimization 
of the system $24,27,28$. In these two cases, the system of constraints seems to shape the network dynamically. Indeed, the hydrological network is gradually formed, as the bronchial network and the vascular network are built during development. However, there is a fundamental difference between the physical principles common to the two classes of networks that explain their structure (global optimization of local constraints), and the mechanisms that build hydrological networks and vasculo-bronchial networks. In the case of the geophysical network of a hydrological system, the system of constraints explaining the functioning of the hydrological network - the form of the network and the characteristics of the flow of water flowing through it - is at the same time the efficient cause of the occurrence of this network. There is therefore an explanatory completeness of the system constituted by the hydrological network and the flow of water which traverses it. The set of constraints formalized within the framework of the constructal theory explains the existence and the evolving structure of this network. It can be said that the system of constraints "creates" the hydrological network. From an experimental point of view, the constructal study of such a network was based not only on the analysis of natural hydrological networks but on networks created in the laboratory by an artificial rain $^{21}$. On the other hand, in the case of biological networks such as vascular and bronchial networks, this same system of constraints, although it explains the functioning of these networks, is not the efficient cause of their existence. The constructal theory can explain the structure of this network, but it does not explain the existence of lungs and, experimentally, the authors did not create a lung in the laboratory by applying a continuous flow of air over an amorphous tissue ${ }^{24}$. In this case, therefore, there is an explanatory incompleteness of the biological circulatory and pulmonary networks (In our comparison of watersheds versus biological networks, we take the example of the lung because the same author has applied the constructal law to river basins ${ }^{24,28}$, but the argument is similar with vascular networks.)

In a non-living hydrologic system, its evolution, i.e., morphologic change upon time, is due to the dissipation of the energy of the water flow. In biology, evolution of a biological system means something else. Actually, there is an ambiguity in the meaning of evolution and its equivalence between living and non-living systems. In "Life and evolution as physics", A. Bejan discusses the meaning of evolution from its Latin etymology ${ }^{23}$. However, the meaning of evolution in life science should be inferred from the history of this word and its use in biology. In biology, "evolution" can have two different meanings (i) developmental morphogenesis of an organism, which is its first signification, and (ii) change over generations, its current meaning. Actually, in the middle of the nineteenth century, when Darwin published his book on the origin of species, the term "evolution" did not refer to transformationist theories like Darwin's, but to some kind of developmental process. Darwin himself did not use the word "evolution" in the current meaning of the word in evolutionary biology until the last edition of his book ${ }^{29,30}$.

If the change upon time of the form of a river basin is equivalent to that of a biological system (for example a bronchoalveolar lung), there is hence an ambiguity in the correspondence: does it correspond to the developmental process of lung morphogenesis in a Mammalian fetus, or the evolutionary process of the emergence of a bronchoalveolar lung from a saccular one? ${ }^{31}$ Additionally, phylogenetic evolution is not the progressive transmutation of one pattern into another but, in most of the cases, a branched process during which the initial pattern persists. Actually, Vertebrate animals with saccular lungs still exist, and, moreover, the Mammalian bronchoalveolar lung is not the only structure that has evolved from the primitive saccular one. Birds have tubular lungs which structure is different from both the bronchoalveolar lung and the saccular one.

The difference in the thermodynamic aspects of living and non-living systems can further be explained in regard to the organization of biological vascular systems. The fact that living entities share a specific kind of self-organization, distinct from physical selforganization, has been discussed by philosophers and scientists since I. Kant ${ }^{32}$ and C. Bernard ${ }^{33}$ to now ${ }^{34-38}$. Due to this organizational singularity, the processes of morphological "change upon time" in watersheds and those of developmental morphogenesis and evolutionary modifications through generations in a population are not thermodynamically equivalent.

Bejan may agree that biological and non-biological systems differ in the causal processes responsible for their respective "change upon time". But, according to Bejan, the explanatory power of the constructal theory is grounded on the epistemological principle that the aim of science is to seek for unification, not for mechanistic explanation.

"The unifying power of the physics of life and evolution is the whole point - the usefulness - of science itself. This quote from Henri Poincaré says it best: the true and only goal of science is to reveal unity rather than mechanism". ${ }^{23}$

However, this epistemological claim regarding the aim of science cannot be generally considered relevant, at least in biological sciences ${ }^{39}$. It may be true that the goal of physics is to subsume each particular case to a general principle (the quest for unity). In this meaning, explanation is the deduction of a particular case from a general law. But this nomological-deductive model of explanation, developed by Hempel ${ }^{40}$, has been shown to 
fail to account for scientific practice in life science. Causal mechanisms ${ }^{41}$, not unity, are the usefulness of biological sciences $^{[i i i]}$. This does not deny any explanatory value of physical principles like the constructal law. Although the constructal theory cannot explain the existence of lungs or vascular systems, there is no doubt that the structures are optimized due to physical constraints ${ }^{[i v]}$. In order to minimize the energy dissipation, the systems must be conventional self-similar fractal ${ }^{42}$. A non-optimized vascular network would be very costly, and the first attempt to link the geometry of blood vessels with the energy costs was made by Murray in $1926^{34}$. To this purpose for the blood flow the Poiseuille's laws were applied whereas the cost was considered as dissipation added to the metabolic rate of energy consumption in blood. This leads to Murray's law that states that minimal dissipation in a bifurcation is reached if the cube of the radius of the mother branch is equal to the sum of the cube of the radii of the daughter branches. In this context the Bejan's constructal theory can be seen as a generalization of these previous approaches ${ }^{43}$.
Mechanistic explanations in biology include physicomathematical models ${ }^{39}$. However, from the biological point of view, the epistemic value of the constructal law is not its unifying power by subsumption of biological processes under a general nomological principle, but, to the contrary, to provide an idealized physicomathematical model of living systems that is embedded in a more general mechanistic explanatory framework. Several explanatory frameworks can be built to respond to specific biological problems (i.e., developmental biology, evolutionary biology, physiopathology), and the explanatory significance of the constructal law will depend on the inclusive explanatory power of the overall framework.

\section{Acknowledgements}

The authors are grateful to Jean Gayon and Matteo Mossio for their constructive remarks. This work was supported financially by the French-Slovenian Hubert-Curien partnership Proteus $n^{\circ} 33325 \mathrm{NL}$ Endothelial planar cell polarity and vascular network structure and functionality.

\section{Endnotes}

[i] In such an organization, the so-called "closed" vascular system, found in humans and numerous other Metazoans, the vasculature is a closed circuitry composed of arteries, capillaries and veins, isolated from the interstitial medium by the endothelial barrier. However, other Metazoans have an "open" vascular system, in which the circuitry is not closed. The arterial network opens in internal cavities that constitute the so-called haemocoel that bathes the internal tissues. We will limit our discussion to the closed circulatory systems.

[ii] We precise "Mammalian" because other taxons may have different types of lungs and circulatory systems, that have not been analyzed by these publications.

[iii] "Mechanism" may have different meanings in philosophy and the different scientific disciplines, including different meanings in biology, as analyzed by Nicholson ${ }^{41}$. We use it here in the meaning of "the causal explanation of a particular phenomenon (causal mechanism)".

[iv] This does not mean that the notion of optimization based on physical constraints is equivalent to evolutionary optimization, which includes other criteria, such as robustness.

\section{References}

1) Harvey W. On the Motion of the Heart and Blood in Animals.: The Harvard Classics. New York: P.F. Collier \& Son, 1909-14; Bartleby.com, 2001. www.bartleby.com/38/3/. 1628.

2) Eckert R. Animal physiology, mechanisms and adaptations. New York: Freeman \& Compagny; 1988.

3) Berne RM, Levy MN, editors. Physiology. St. Louis: Mosby; 1998.

4) Caro CG, Pedley TJ, Schroter RC, Seed WA. The mechanics of the circulation. Cambridge: Cambridge University Press; 2012.
5) Fung YC. Biomechanics Circulation. New York: Springer; 2010 .

6) Fernel J. De naturali parte medicinae libri septem. Lyon; 1551.

7) Fernel J. La Physiologie. Kany-Turpin, J. ed. Paris: Fayard, $2001 ; 1655$.

8) Strahler A. Quantitative analysis of watershed geomorphology. Eos, Transactions American Geophysical Union 1957;38(6):913-20.

9) Cassot F, Lauwers F, Lorthois S, Puwanarajah P, CancesLauwers V, Duvernoy H. Branching patterns for arterioles and venules of the human cerebral cortex. Brain Res 2009;1313:62-78.

10) Cassot F, Lauwers F, Lorthois S, Puwanarajah P, Duvernoy H. Scaling laws for branching vessels of human cerebral cortex. Microcirculation 2009;16(4):331-44, 2 p following 344.

11) Horsfield K. Morphology of the bronchial tree in the dog. Respir Physiol 1976;26(2):173-82.

12) Horsfield K. Some mathematical properties of branching trees with application to the respiratory system. Bull Math Biol 1976;38(3):305-15.

13) Markovic R, Peltan J, Gosak M, Horvat D, Zalik B, Seguy B, et al. Planar cell polarity genes frizzled4 and frizzled6 exert patterning influence on arterial vessel morphogenesis. PLoS One 2017;12(3):e0171033.

14) Lopes R, Betrouni N. Fractal and multifractal analysis: a review. Med Image Anal 2009;13(4):634-49.

15) Losa GA. The fractal geometry of life. Riv Biol 2009;102(1):29-59.

16) Cross SS, Start RD, Silcocks PB, Bull AD, Cotton DW, Underwood JC. Quantitation of the renal arterial tree by fractal analysis. J Pathol 1993;170(4):479-84. 
17) Lorthois S, Cassot F. Fractal analysis of vascular networks: insights from morphogenesis. J Theor Biol 2009;262(4):614-33.

18) Al-Rawi M, Al-Jumaily AM. Assessing abdominal aorta narrowing using computational fluid dynamics. Med Biol Eng Comput 2016;54(5):843-53.

19) Tawhai MH, Burrowes KS. Modelling pulmonary blood flow. Respir Physiol Neurobiol 2008;163(1-3):150-7.

20) Bejan A, Lorente S. The constructal law and the thermodynamics of flow systems with configuration. International journal of heat and mass transfer. International journal of heat and mass transfer 2004; 47:3203-3214.

21) Bejan A, Lorente $\mathrm{S}$. The constructal law of design and evolution in nature. Philos Trans R Soc Lond B Biol Sci 2010;365(1545):1335-47.

22) Bejan A, Lorente S. The constructal law and the evolution of design in nature. Phys Life Rev 2011;8(3):209-40.

23) Bejan A. Life and evolution as physics. Commun Integr Biol 2016;9(3):e1172159.

24) Reis AH, Miguel AF, Aydin M. Constructal theory of flow architecture of the lungs. Med Phys 2004;31(5):1135-40.

25) Dai W. Constructal Theory Applied to Vascular Countercurrent Networks In: Rocha LAO, Lorente S, Bejan A, editors. Constructal Law and the Unifying Principle of Design. New York: Springer; 2013. p. 143-160.

26) Hadjistassou C, Bejan A, Ventikos Y. Cerebral oxygenation and optimal vascular brain organization. $\mathrm{J}$ R Soc Interface 2015;12(107).

27) Razavi MS, Shirani E, Salimpour MR, Kassab GS. Constructal law of vascular trees for facilitation of flow. PLoS One 2014;9(12):e116260.

28) Reis AH. Constructal view of scaling laws of river basins. Geomorphology 2006;78:201-206.

29) Darwin C. The origins of species by means of natural selection, or the preservation of favoured races in the struggle for life. London: John Murray; 1859.
30) Darwin C. De l'origine des espèces ou des lois du progès chez les êtres organisés. Trad. C.-A. Royer. Paris: Guillaumin et Cie et Masson \& fils; 1862.

31) Roux E. Origine et évolution de l'appareil respiratoire aérien des Vertébrés [Origin and evolution of the respiratory tract in vertebrates]. Rev Mal Respir 2002;19(5 Pt 1):601-15.

32) Kant I. Critique of judgement (English translation H.J. Bernard, 1892). London: McMillan and Co, 1914; 1790.

33) Bernard C. introduction à l'étude de la médecine expérimentale. Paris: Flammarion, 1997; 1865.

34) Karsenti E. Self-organization in cell biology: a brief history. Nat Rev Mol Cell Biol 2008;9(3):255-62.

35) Mossio M, Moreno A. Organisational closure in biological organisms. Hist Philos Life Sci 2010;32(2-3):269-88.

36) Montevil M, Mossio M. Biological organisation as closure of constraints. Journal of Theoretical Biology 2015;372:179-191.

37) Montevil M, Mossio M, Pocheville A, Longo G. Theoretical principles for biology: Variation. Prog Biophys Mol Biol 2016;122(1):36-50.

38) Mossio M, Montevil M, Longo G. Theoretical principles for biology: Organization. Prog Biophys Mol Biol 2016;122(1):24-35.

39) Brigandt I. Explanation in biology: reduction, pluralism, and explanatory aims. Sci \& Educ 2013;22:69-91.

40) Hempel C. The logic of functional analysis. In: Aspects of scientific explanation. New York: Free Press; 1965. p. 297-330.

41) Nicholson DJ. The concept of mechanism in biology. Stud Hist Philos Biol Biomed Sci 2012;43(1):152-63.

42) West GB, Brown JH, Enquist BJ. A general model for the origin of allometric scaling laws in biology. Science 1997;276(5309):122-6.

43) Moreau B, Mauroy B. Functional optimization of the arterial network. No. arXiv: 1405.1281 2014. 